\title{
Análise da convergência da produtividade da mão-de-obra agropecuária entre os estados brasileiros: aplicação de matrizes de Markov, 1990-2000
}

Adelar Fochezatto ${ }^{1}$

Valter J. Stülp ${ }^{2}$

Resumo: O objetivo deste trabalho é analisar a convergência da produtividade do trabalho da agropecuária brasileira na década de noventa, comparando-a com a de outros setores e projetando seu comportamento relativo usando cadeias de Markov. Os resultados indicaram que a produtividade do trabalho na agropecuária não está convergindo, sendo que alguns estados evoluem para o nível superior de produtividade e outros para o nível inferior. Pode-se dizer, portanto, que neste setor está havendo dois clubes de convergência. Em relação aos demais setores, está havendo convergência de produtividade em cinco dos oito setores analisados: em três setores a produtividade convergiu para a classe de menor produtividade, em um setor ela convergiu para as duas classes de menor produtividade e no outro setor ela convergiu para a classe de maior produtividade. Em geral, o tempo de convergência foi bastante longo, indicando que os fatos econômicos do período em questão não tiveram maiores repercussões sobre este processo.

Palavras-chaves: agropecuária, produtividade da mão-de-obra, convergência, modelo de Markov.

\footnotetext{
${ }^{1}$ Doutor em economia e professor titular da PUC-RS. E-mail: adelar@pucrs.br

${ }^{2} \mathrm{PhD}$ em economia agrícola e professor da PUC-RS. E-mail: stulp@terra.com.br
} 
Abstract: The study analyzes the convergence of the labor productivity in the Brazilian agricultural sector in the nineties, comparing it with its productivity in the other sectors and projecting its future behavior through Markov matrices. The results indicate that the Brazilian states are diverging in the labor productivity in the agricultural sector. Some states will move to a high level and others to a low level of labor productivity. In five of the other sectors of the Brazilian economy there will be a convergence of the states with regard to the labor productivity. In three of these five sectors the states will converge to a low level of labor productivity; in one sector they will converge to two classes of low productivity and in another sector the states will move to a class of high productivity. The time required for convergence of the Brazilian states is very long; indicating that the economic factors prevailing during the period on which the analysis is based did not impact very strongly on this process.

Key words: agricultural, labor productivity, convergence, Markov model.

\section{Introdução}

Após um período de economia relativamente fechada e de altas taxas de inflação, o Brasil, a partir da década de 90, entrou em uma fase de abertura comercial e de estabilização macroeconômica. Neste período, a tarifa média de importação diminuiu significativamente e, em 1994, foi lançado o Plano Real, o qual foi acompanhado por uma política de controle cambial com forte apreciação da moeda doméstica. Na primeira fase do Plano Real, que vai de 1994 a 1999, embora tenha ocorrido uma pequena desvalorização nominal, a moeda doméstica permaneceu valorizada. $\mathrm{O}$ ajuste cambial aconteceu com a mudança de regime no início de 1999, quando o País passou a adotar o sistema de câmbio flexível.

No que se refere à abertura comercial, Pinheiro et al. (2001) afirma que, no período de 1988 a 1995, a tarifa média sobre as importações baixou de $51 \%$ para $12 \%$, a maioria das barreiras não-tarifárias foi eliminada e acabou a reserva de mercado para os setores da informática. A liberalização do comércio, além de aumentar a integração do País à economia mundial, estimulou a modernização tecnológica e o incremento 
da produtividade. De acordo com Muendler (2001), o acirramento da concorrência e a facilidade de acesso ao capital estrangeiro estimularam produtores domésticos a aumentar sua competitividade. O resultado disso foi um aumento relativo de recursos da economia alocados para os setores transacionáveis.

Em 1994, o Brasil implementou o Plano Real com o objetivo de promover a estabilização macroeconômica. Para controlar os preços, o Plano valeu-se especialmente das seguintes medidas de política econômica: controle da taxa de câmbio e controle da oferta de moeda. A combinação que vigorou no período de 1994 a 1999 foi a de baixa taxa de câmbio nominal, restrição monetária e elevada taxa de juros. Isto provocou a queda dos preços, o aumento das importações e o aumento do déficit público. A redução da inflação, por sua vez, aumentou a demanda agregada doméstica, possibilitando, em algum grau, a substituição de importações e o aumento das exportações.

A estabilização dos preços, portanto, influenciou positivamente alguns setores produtivos e negativamente, outros. Em linhas gerais, pode-se afirmar que os setores relativamente mais beneficiados foram: a) os setores mais dependentes de insumos importados; b) os setores com maior elasticidade de substituição de insumos domésticos por importados; c) os setores com menor elasticidade de substituição do produto final doméstico pelo importado; e d) os setores com produção voltada ao mercado doméstico.

A abertura comercial, via redução de tarifas, e a estabilização macroeconômica, através do controle cambial, além de contribuírem de forma decisiva para o controle da inflação, alteraram a estrutura de preços relativos dos produtos domésticos entre si e em relação aos produtos importados. Isto porque os setores produtivos, por apresentarem diferenças nas estruturas de custos e nos mecanismos de mercado, sofrem efeitos diferenciados quando ocorrem mudanças nas políticas econômicas.

Por isso, pode-se dizer que essas mudanças macroeconômicas influenciaram a estrutura setorial e espacial da produção, bem como a sua produtividade. Em teoria, a abertura da economia provoca uma maior especialização produtiva regional, intensificando as interdependências econômicas entre os estados. Isso porque tende a provocar uma melhor utilização das vantagens comparativas por parte das economias 
Análise da convergência da produtividade da mão-de-obra agropecuária entre os estados brasileiros: aplicação de matrizes de Markov, 1990-2000

regionais, levando à geração de excedentes exportáveis nesses setores e à importação em outros em que apresenta baixa competitividade. Em suma, as políticas macroeconômicas da década de noventa, por terem alterado os preços relativos dos produtos e a alocação de recursos, certamente influenciaram a composição da estrutura produtiva, em termos de setores e regiões, e a produtividade dos fatores.

O objetivo deste trabalho é analisar a convergência da produtividade do trabalho do setor agropecuário entre os estados brasileiros na década de 1990. Especificamente, compara-se a evolução da produtividade da mão-de-obra ocupada no setor agropecuário com a da mão-de-obra ocupada em outros sete setores da economia brasileira. Esta produtividade é aqui definida como o valor adicionado bruto a preços básicos do setor dividido pelo número de pessoas ocupadas no mesmo.

Para analisar a convergência, utiliza-se um processo estacionário de primeira ordem de Markov, descrito detalhadamente na metodologia. Com esta técnica, é possível verificar se está ou não ocorrendo convergência, o tempo necessário para alcançá-la, a evolução da posição relativa dos estados dentro da distribuição regional da produtividade e a formação ou não de clubes de convergência.

O estudo abrange os vinte e sete estados brasileiros e refere-se ao período de 1990 a 2000. Para cada estado é calculado o produto por trabalhador referente aos biênios 1990/91 e 1999/00, sendo que estes valores são expressos em termos relativos à média do Brasil no período em questão.

Além desta introdução, na segunda seção, é apresentada de forma detalhada a metodologia utilizada. Na terceira seção são analisados os resultados encontrados e, por último, serão apresentadas as principais conclusões do trabalho.

\section{Material e métodos}

Os estudos sobre convergência de renda entre países e regiões têm ocupado um grande espaço na literatura econômica nos últimos anos. A questão fundamental que se coloca nestes estudos é a de saber se as economias têm tendência a convergir em direção aos mesmos níveis de renda (ou produto) per capita, ou seja, se existe um diferencial de 
crescimento que possibilita que as economias menos desenvolvidas alcancem o nível de renda per capita das economias mais desenvolvidas (Baumol, 1986; Barro e Sala-i-Martin, 1991, 1992). Para isso, existem diversos métodos para a análise empírica da convergência entre países e regiões, tais como o da $\beta$-convergência, da $\sigma$-convergência e convergência estocástica, descritos na literatura especializada (Barro e Sala-iMartin, 1995; Bernard e Durlauf 1995).

Apesar de amplamente usadas, com um grande número de estudos aplicados para países e regiões, estas metodologias de estudo da convergência não estão imunes a críticas, tanto em relação aos seus fundamentos teóricos quanto aos seus resultados empíricos. Na perspectiva teórica, a principal crítica refere-se à suposição de retornos decrescentes dos fatores de produção, decorrente da sua fundamentação nos modelos de crescimento neoclássicos. Neste sentido, a teoria do crescimento endógeno tem desafiado esta suposição ao afirmar, e evidenciar empiricamente, a existência de rendimentos crescentes. Em termos empíricos, as críticas se referem, dentre outras, à possibilidade de haver inconsistência entre os conceitos de $\beta$ e $\sigma$ convergência (Friedman,1992; Quah 1993b), lançando dúvidas sobre a interpretação dos resultados. Outra crítica é a de que essas técnicas são incapazes de mostrar o comportamento da distribuição da renda ao longo do tempo, impossibilitando a verificação da dinâmica em termos de posição relativa das regiões no processo de convergência.

Neste estudo é utilizada uma abordagem alternativa, com o intuito de preencher essas lacunas existentes nos conceitos de $\beta$ e $\sigma$ convergência. Para isso, o estudo utiliza um processo estacionário de primeira ordem de Markov, com o qual se pode verificar se está ou não ocorrendo convergência, o tempo necessário para alcançá-la, a evolução da posição relativa das regiões dentro da distribuição da produtividade e a formação ou não de clubes de convergência.

A aplicação do processo estacionário de primeira ordem de Markov exige que se construa uma matriz de probabilidades de transição das regiões entre as diferentes classes de produtividade. Para isso, é preciso calcular valores de produtividade para pelo menos dois pontos no tempo. Os dois momentos do tempo aqui considerados são os biênios de 1990/1991 e 1999/2000. As informações utilizadas para apurar a produtividade do setor agropecuário e dos demais setores usados 
Análise da convergência da produtividade da mão-de-obra agropecuária entre os estados brasileiros: aplicação de matrizes de Markov, 1990-2000

como comparativos ${ }^{3}$ são o produto setorial (valor adicionado a preços básicos) das Contas Regionais e o Pessoal Ocupado setorial dos Censos Demográficos, ambos do Instituto Brasileiro de Geografia e Estatística (IBGE). Os valores de 1990 foram inflacionados para o ano de 1991 e os de 1999, para o ano de 2000, por meio do índice geral de preços (IGPDI) da Fundação Getúlio Vargas. Após, calculou-se, para o biênio inicial e para o final, a produtividade da mão-de-obra setorial, dividindo-se o valor adicionado anual médio do biênio pela respectiva média anual de pessoas ocupadas.

Para cada setor, a produtividade de cada estado foi ponderada, tanto no biênio inicial como no final, em relação à média nacional considerada igual a 1,00. Assim, para cada setor, os estados foram organizados em uma mesma estrutura de classes de níveis de produtividade da mãode-obra tanto em relação ao biênio inicial quanto ao final ${ }^{4}$. Com esse procedimento, foi possível examinar como os estados migraram de uma classe para outra e, com base nestas migrações, foi construída a matriz de probabilidades de transição dos mesmos entre classes de produtividade da mão-de-obra. Essa matriz é definida como sendo a matriz de probabilidades de transição de Markov 5 .

Para a organização da estrutura de classes de níveis de produtividade, foi inicialmente tentado o procedimento sugerido por Magrini (1999). Assim, procedeu-se ao teste de normalidade de cada uma das duas distribuições de produtividade de cada setor, através do teste de Kolmogorov-Smirnov. Para isso, comparou-se a distribuição de freqüência acumulada observada com a acumulada teórica esperada na hipótese

\footnotetext{
${ }^{3}$ Estes setores são: Setor 1: Agropecuária; Setor 2: Indústria extrativa mineral, indústria de transformação, eletricidade, gás e água; Setor 3: Construção civil; Setor 4: Comércio e reparação de veículos, de objetos pessoais e de uso doméstico, alojamento e alimentação; Setor 5: Transportes, armazenagem e comunicações; Setor 6: Intermediação financeira, atividades imobiliárias, aluguéis, serviços prestados às empresas, saúde e educação mercantis e serviços domésticos; Setor 7: Administração pública, defesa e seguridade social; e Setor 8: Outros serviços coletivos, sociais e pessoais.

${ }^{4}$ Estes valores e a classificação dos estados encontram-se no Anexo C.

${ }^{5}$ Para o setor agropecuário, o estado do Amazonas foi excluído da matriz, visto que ele apresenta um comportamento atípico se comparado aos demais estados. No primeiro biênio, ele se encontra na classe 3 , com produtividade relativa à média nacional de 0,87 e, no biênio final, ele se situa na classe 1 , com uma das produtividades relativas mais baixas, de 0,28 (ver anexo C).
} 
de normalidade. O valor absoluto da diferença máxima entre as duas constitui o valor $D$ para o teste de Kolmogorov-Smirnov (Siegel, 1956).

A hipótese de normalidade da distribuição não foi rejeitada ao nível de significância de $10 \%$ em relação a todos os setores, nos dois biênios, com exceção da distribuição do biênio inicial do Setor 6. A rejeição da hipótese de normalidade, mesmo ao nível de $1 \%$, para esta distribuição deve-se ao valor elevado da produtividade da mão-de-obra no Distrito Federal $(7,59)$. Excluindo esta observação, a hipótese de normalidade é aceita também para esta distribuição.

Estimou-se, a seguir, a função densidade de probabilidade de cada distribuição da produtividade. Esta função pode ser estimada como:

$$
\hat{f}(x)=\frac{1}{n h} \sum_{i=1}^{n} I\left(x-\frac{h}{2} \leq x_{i} \leq x+\frac{h}{2}\right)
$$

no qual $I\left(x-\frac{h}{2} \leq x_{i} \leq x+\frac{h}{2}\right)$ é igual a 1 se $x_{i}$ se encontrar no intervalo $(x-h / 2, x+h / 2)$ e igual a zero em caso contrário (Pagan e Ullah, 1999). A função $\hat{f}(x)$ é a freqüência relativa por unidade no intervalo $(x$ $-h / 2, x+h / 2$ ) e é a ordenada do histograma no ponto $x$. Cada ponto $x$ representa o centro de um intervalo. $O$ n é o número total de observações que, neste estudo, é igual a 27 (número total de estados brasileiros).

O valor de $h$, a dimensão do intervalo de classe, é importante para a estimativa da função densidade de probabilidade. Um $h$ muito grande faz com que haja um grande número de pontos em cada intervalo, diminuindo a variância da estimativa. No entanto, isto leva a um formato de histograma menos adequado, visto que aumenta o viés da estimativa. Com um $h$ pequeno ocorre o contrário: reduz o viés, mas aumenta a variância (Pagan e Ullah, 1999).

Portanto, o valor de $h$ deve ser escolhido de modo a resultar em um trade-off ótimo, entre viés e variância da estimativa. Para encontrar este valor, pode-se utilizar o mesmo procedimento de Devroye e Györfi (1985, apud Magrini 1999, p.264), que minimizam a integral do erro absoluto (IAE), dada por:

$$
I A E=\int_{-\infty}^{\infty}|\hat{f}(x)-f(x)| d x
$$


Análise da convergência da produtividade da mão-de-obra agropecuária entre os estados brasileiros: aplicação de matrizes de Markov, 1990-2000

Com base neste procedimento, aqueles autores concluem que, quando a distribuição é normal, o valor ótimo do intervalo de classe é dado por:

$$
h=2,72 s n^{-1 / 3}
$$

sendo $s$ o desvio-padrão da distribuição e $n$ o número de observações. Segundo os autores, esta expressão para encontrar o valor de $h$ seria adequada mesmo nos casos em que as observações não seguissem uma distribuição normal.

Com a utilização do $h$ determinado por esta fórmula, as classes de produtividade formadas em relação às várias distribuições apresentavam um número de observações muito distinto. Em uma mesma distribuição havia uma ou duas classes com poucas observações e outras com muitas observações.

Le Gallo (2001, p.10) enfatiza que as classes devem ser escolhidas de modo que as da distribuição do período inicial tenham um número aproximadamente igual de observações. Nesta mesma linha, Fingleton (1999), embora faça referência ao método de Magrini, para evitar classes iniciais com poucas observações, decide usar outro critério, formando quatro classes, sendo uma com os valores abaixo de $75 \%$ da média (regiões pobres), outra com valores entre $75 \%$ e $100 \%$, a seguinte com observações entre $100 \%$ e $125 \%$ e a última, com valores acima de $125 \%$ da média (regiões ricas).

Neste estudo, procurou-se, em relação a cada setor, dividir as observações da distribuição inicial em quatro classes com um número aproximadamente igual de observações, seguindo a recomendação de Le Gallo (2001). Nas distribuições iniciais, ou seja, as do biênio 1990/1991, começou-se a contar o número de observações a partir da de valor mais baixo. Na sétima observação terminaria a primeira classe, iniciando-se a segunda que seria composta pelas sete observações seguintes. E assim se procederia com a terceira e quarta classes. Porém, quando a diferença entre o valor da última observação de uma classe e o da primeira da classe seguinte era muito pequena, aumentou-se ou diminuiu-se o número de observações das classes para um máximo de nove ou um mínimo de cinco observações, de modo que houvesse um hiato maior entre as duas classes contíguas (ver Anexo C). 
O ponto médio do hiato entre duas classes contíguas na distribuição inicial é o valor de referência para a distribuição das observações entre as classes na distribuição final. Assim, por exemplo, o ponto médio do hiato entre a primeira e a segunda classe na distribuição inicial do Setor 1 (de 0,49 a 0,59) é 0,54 . Portanto, na distribuição final, todas as observações com valor inferior a 0,54 estão na primeira classe.

Estabelecidas as classes de níveis de produtividade, foi verificado quantos estados migraram de uma classe para outra, ou permaneceram na mesma, entre o biênio de 1990/1991 e o de 1999/2000. Com isso, se estimaram as matrizes de probabilidades de transição, ou matrizes de Markov. A partir dessas matrizes, se construíram sistemas de equações de diferenças. Neste sistema, considera-se $F_{t}$ como a distribuição estadual da produtividade da mão-de-obra no tempo $t, M$ a matriz de transição de Markov, indicando a probabilidade de cada estado na classe de produtividade $i$ no tempo $t$ estar na classe $j$ no tempo $t+1$ e $F_{t+1}$ a distribuição estadual da produtividade no tempo $t+1$. Assim, o sistema de equações, que expressa a evolução da distribuição ao longo do tempo, pode ser representado por:

$$
F_{t+1}=M F_{t}
$$

A hipótese básica associada a este procedimento é a de que as probabilidades de transição sejam estacionárias, isto é, que a probabilidade de passagem de uma classe para outra seja invariável no tempo. Assim, a partir da expressão (4) e utilizando-se os dados do Anexo C chegou-se ao sistema de equações de diferenças propriamente dito.

Para resolver um sistema de equações de diferenças determinam-se as raízes características e os vetores característicos do sistema de equações. No caso de raízes características reais e distintas, a solução geral do sistema de equações de diferenças é dada por $F_{t}=c_{1} r_{1}^{t} v_{1}+c_{2} r_{2}^{t} v_{2}$ $+c_{3}{ }^{r} v_{3}+c_{4} r_{4}^{r} v_{4}$, no qual $F_{t}$ é o vetor das participações relativas dos estados em cada classe de produtividade no tempo, $t, r_{i}$ são as raízes características, $v_{i}$ os vetores característicos e $c_{i}$ são constantes determinadas a partir das condições iniciais do sistema ${ }^{6}$, ou seja, os valores de $F_{t}$ no tempo $t=0$. Estes valores de $F_{t}$ no tempo inicial são as participações relativas dos estados em cada classe na distribuição inicial da produtividade do trabalho dos estados.

${ }^{6}$ Ver Simon e Blume (2004), cap. 23. 
Análise da convergência da produtividade da mão-de-obra agropecuária entre os estados brasileiros: aplicação de matrizes de Markov, 1990-2000

A solução do sistema gerou as informações referentes aos processos de convergência da produtividade da mão-de-obra entre os estados no longo prazo, bem como a velocidade destas convergências (ver Anexo A). Cada solução informa quantas classes de níveis de produtividade existirão no longo prazo, possibilitando que se identifique a existência, ou não, de convergência.

A segunda raiz característica, em valor absoluto, de cada solução, fornece uma medida da velocidade com que o equilíbrio de longo prazo é alcançado. Essa velocidade é entendida como o tempo necessário para percorrer a metade da distância entre a posição inicial e a de equilíbrio de longo prazo (Dm). Ela é dada por Dm $=-\log 2 / \log \left|r_{2}\right|$.

\section{Resultados e discussão}

\subsection{A produtividade da mão-de-obra setorial nos estados brasileiros: constatações e comparações relativas à década de 90}

O desempenho macroeconômico na década de noventa foi marcado por baixo crescimento econômico e por importantes reformas estruturais, com destaque para a abertura comercial e financeira, a estabilização macroeconômica e a reforma do estado, as quais ocasionaram fortes ajustes microeconômicos no âmbito dos setores produtivos. O objetivo deste trabalho é avaliar um aspecto desses possíveis ajustes: a evolução da produtividade do trabalho no setor da agropecuária e verificar se houve convergência ou não nessa evolução entre os estados brasileiros.

Conforme a Tabela 1, o crescimento da produtividade do trabalho na agropecuária na década de 90 foi de aproximadamente $13 \%$. No entanto, analisando os resultados para as diferentes unidades da federação, observam-se desempenhos bem distintos: em geral ela cresceu mais fortemente nos estados do Centro-Oeste, Sul e Sudeste e menos nos estados do Nordeste. Em termos de produtividade dos estados em relação à média nacional, a mesma separação pode ser feita.

Estes ganhos de produtividade não aconteceram de forma uniforme entre os setores econômicos e regiões brasileiras. A Tabela 2 mostra que, em termos setoriais, cinco setores apresentaram crescimento da produtividade do trabalho acima da média nacional (setores 1, 2, 5, 6 
e 7) e três abaixo (setores 3, 4 e 8). Em termos regionais, os estados que tiveram produtividade do trabalho acima da média foram aqueles relativamente mais desenvolvidos: os estados das regiões Sudeste, Sul e Centro-Oeste. Em suma, os dados referentes à produtividade do trabalho setorial na década de noventa mostram que o crescimento verificado foi no sentido de aumentar ainda mais as diferenças entre os estados.

O setor agropecuário é um exemplo disso. Ele mostrou a existência de uma forte dualidade em termos de produtividade do trabalho: um grupo de estados evoluiu para a classe de menor produtividade e o outro para a de maior produtividade. $\mathrm{O}$ primeiro grupo sendo formado pelos estados das regiões Norte e Nordeste e o estado do Espírito Santo e o segundo pelos estados das regiões Sul, Sudeste (exclusão do Espírito Santo) e Centro-Oeste, além dos estados do Pará e Amapá.

Observando a Tabela 2 e o Anexo C, é possível identificar alguns aspectos importantes. Em primeiro lugar, a maioria dos estados que melhoraram sua posição relativa no período analisado, já estava em uma situação relativamente melhor no início do período. Este comportamento revela que o cenário macroeconômico do período não reduziu as disparidades de produtividade do trabalho entre estados.

Outro aspecto a ser destacado é o de que nos estados em que a produtividade do trabalho era relativamente superior no início do período, houve melhoria em sua posição relativa em um maior número de setores. Este fato pode revelar a existência de uma maior harmonia em termos de performance setorial, a qual pode estar influenciando positivamente a produtividadeatravés demaiores possibilidades degeração deexternalidades positivas decorrentes da interação entre os segmentos produtivos.

Na Tabela 2, observa-se, também, que o Setor 6 (Intermediação financeira, atividades imobiliárias, aluguéis, serviços prestados às empresas, saúde e educação mercantis e serviços domésticos) foi o que melhorou sua posição relativa em um maior número de estados. Os Setores 2 (Indústria extrativa mineral, indústria de transformação, eletricidade, gás e água) e 3 (Construção civil) também tiveram uma melhoria de posição relativa em um número expressivo de estados, o que levaria a concluir que esses setores estão tendendo a uma convergência para uma classe de maior produtividade. Isso, no entanto, não está acontecendo, como será visto na próxima seção. Por enquanto, o que 
se pode dizer em relação a esses setores é que os mesmos apresentam um melhor desempenho relativo, que, por sua vez, está acontecendo de forma mais dispersa em termos regionais.

Tabela 1 - Produtividade do trabalho da agropecuária, Brasil e estados, 19902000

\begin{tabular}{|c|c|c|c|c|c|}
\hline \multirow[t]{2}{*}{ Estados } & \multicolumn{3}{|c|}{$\begin{array}{c}\text { Produtividade } \\
\text { (R\$/Pessoa Ocupada) }\end{array}$} & \multicolumn{2}{|c|}{$\begin{array}{c}\text { Produtividade } \\
\text { relativa (Estado/Brasil) }\end{array}$} \\
\hline & 1991 & 2000 & Var (\%) & 1991 & 2000 \\
\hline Rondônia & 3.642 & 4.744 & 30,3 & 0,629 & 0,727 \\
\hline Acre & 1.613 & 1.560 & $-3,3$ & 0,278 & 0,239 \\
\hline Amazonas & 5.025 & 1.833 & $-63,5$ & 0,867 & 0,281 \\
\hline Roraima & 2.472 & 1.795 & $-27,4$ & 0,427 & 0,275 \\
\hline Pará & 11.634 & 7.152 & $-38,5$ & 2,008 & 1,097 \\
\hline Amapá & 6.472 & 6.124 & $-5,4$ & 1,117 & 0,939 \\
\hline Tocantins & 2.225 & 3.000 & 34,8 & 0,384 & 0,460 \\
\hline Maranhão & 1.762 & 1.723 & $-2,2$ & 0,304 & 0,264 \\
\hline Piauí & 1.229 & 1.320 & 7,4 & 0,212 & 0,202 \\
\hline Ceará & 2.709 & 1.654 & $-39,0$ & 0,468 & 0,254 \\
\hline Rio Grande do Norte & 2.539 & 1.273 & $-49,8$ & 0,438 & 0,195 \\
\hline Paraíba & 2.757 & 2.789 & 1,1 & 0,476 & 0,428 \\
\hline Pernambuco & 3.390 & 3.317 & $-2,1$ & 0,585 & 0,500 \\
\hline Alagoas & 3.457 & 1.961 & $-43,3$ & 0,597 & 0,301 \\
\hline Sergipe & 3.527 & 2.751 & $-22,0$ & 0,609 & 0,422 \\
\hline Bahia & 2.815 & 3.082 & 9,5 & 0,486 & 0,473 \\
\hline Minas Gerais & 5.963 & 5.974 & 0,2 & 1,029 & 0,916 \\
\hline Espírito Santo & 3.469 & 4.706 & 35,7 & 0,599 & 0,722 \\
\hline Rio de Janeiro & 5.446 & 6.180 & 13,5 & 0,940 & 0,948 \\
\hline São Paulo & 14.700 & 17.465 & 18,8 & 2,537 & 2,678 \\
\hline Paraná & 5.625 & 10.865 & 93,2 & 0,971 & 1,666 \\
\hline Santa Catarina & 8.259 & 11.442 & 38,5 & 1,425 & 1,754 \\
\hline Rio Grande do Sul & 8.965 & 11.147 & 24,3 & 1,547 & 1,709 \\
\hline Mato Grosso do Sul & 14.407 & 19.496 & 35,3 & 2,486 & 2,989 \\
\hline Mato Grosso & 4.353 & 12.606 & 189,6 & 0,751 & 1,933 \\
\hline Goiás & 6.290 & 10.222 & 62,5 & 1,085 & 1,567 \\
\hline Distrito Federal & 17.685 & 9.517 & $-46,2$ & 3,052 & 1,459 \\
\hline Brasil & 5.794 & 6.522 & 12,6 & 1 & 1 \\
\hline
\end{tabular}

Fonte dos dados brutos: IBGE, Contas Nacionais e Censos Demográficos de 1991 e 2000. Obs. Os valores foram atualizados para $\mathrm{R} \$$ de 2000. 
Tabela 2 - Variação da posição relativa dos setores nos estados brasileiros e em relação a média nacional, 1990-2000

\begin{tabular}{|c|c|c|c|c|c|c|c|c|c|}
\hline \multirow{2}{*}{ Estados } & \multicolumn{8}{|c|}{ Setores } & \multirow{2}{*}{$\begin{array}{c}\text { Total de } \\
\text { setores }\end{array}$} \\
\hline & 8 & 5 & 4 & 7 & 1 & 3 & 2 & 6 & \\
\hline Maranhão & - & - & - & - & - & - & - & - & $\mathbf{0}$ \\
\hline Acre & - & - & - & + & - & - & - & - & 1 \\
\hline Roraima & - & - & - & - & - & - & + & - & 1 \\
\hline Sergipe & - & - & - & - & - & - & - & + & 1 \\
\hline Amapá & - & - & - & - & - & - & + & - & 1 \\
\hline Pará & - & - & - & - & - & - & - & + & 1 \\
\hline Piauí & - & - & - & - & - & + & - & + & 2 \\
\hline Paraíba & - & - & - & - & - & - & + & + & 2 \\
\hline Bahia & - & - & - & - & - & + & + & - & 2 \\
\hline Amazonas & + & - & - & - & - & - & - & + & 2 \\
\hline Goiás & - & - & - & - & + & + & - & - & 2 \\
\hline Tocantins & - & - & - & - & + & + & + & - & 3 \\
\hline Rio Grande do Norte & - & - & - & - & - & + & + & + & 3 \\
\hline Rio de Janeiro & - & - & - & - & + & - & + & + & 3 \\
\hline Mato Grosso do Sul & - & - & + & - & + & - & + & - & 3 \\
\hline Distrito Federal & + & + & - & - & - & - & + & - & 3 \\
\hline Santa Catarina & - & - & - & - & + & + & - & + & 3 \\
\hline Pernambuco & - & + & + & + & - & + & - & - & 4 \\
\hline Alagoas & - & + & - & + & - & - & + & + & 4 \\
\hline Rondônia & - & + & - & - & + & - & + & + & 4 \\
\hline Paraná & - & - & + & + & + & - & - & + & 4 \\
\hline Ceará & - & + & + & + & - & + & - & + & 5 \\
\hline Mato Grosso & - & - & + & + & + & + & + & - & 5 \\
\hline Rio Grande do Sul & + & - & + & + & + & - & - & + & 5 \\
\hline Minas Gerais & + & + & - & + & - & + & + & + & 6 \\
\hline São Paulo & + & - & + & + & + & + & - & + & 6 \\
\hline Espirito Santo & + & + & + & + & + & + & - & + & 7 \\
\hline Média nacional & - & + & - & + & + & - & + & + & 7 \\
\hline Total de Estados & 6 & 7 & 8 & 10 & 11 & 12 & 13 & 16 & \\
\hline
\end{tabular}

Fonte: Elaboração dos autores a partir do Anexo C. 
Análise da convergência da produtividade da mão-de-obra agropecuária entre os estados brasileiros: aplicação de matrizes de Markov, 1990-2000

Nome dos setores: 1) Agropecuária; 2) Indústria extrativa mineral; Indústria de transformação; e Eletricidade, gás e água; 3) Construção; 4) Comércio e reparação de veículos e de objetos pessoais e de uso doméstico; e Alojamento e alimentação; 5) Transportes e armazenagem; e Comunicações; 6) Intermediação financeira; Atividades imobiliárias, aluguéis e serviços prestados às empresas; Saúde e educação mercantis; e Serviços domésticos; 7) Administração pública, defesa e seguridade social; 8) Outros serviços coletivos, sociais e pessoais.

Nota: o sinal positivo indica uma melhoria de posição relativa e o sinal negativo o contrário. Os valores que aparecem na última linha e coluna referem-se ao número de sinais positivos ao longo das respectivas linhas e colunas.

O mesmo não se pode afirmar em relação aos Setores 4 (Comércio e reparação de veículos e de objetos pessoais e de uso doméstico, e Alojamento e alimentação), 5 (Transportes, armazenagem e comunicações), 7 (Administração pública, defesa e seguridade social) e 8 (Outros serviços coletivos, sociais e pessoais), os quais pioraram sua posição relativa na maioria dos estados ao longo do período. Diferentemente dos setores referidos acima, para esses se esperaria uma convergência para classes de menor produtividade do trabalho, sendo ela comandada, principalmente, pelos estados que já se encontravam em uma situação desvantajosa no início do período, especialmente do Norte e Nordeste.

O Setor 1 (Agropecuária) está numa posição intermediária. Sua posição relativa melhorou em um número expressivo de estados. O resultado final, no entanto, como será visto posteriormente, mostra a existência de uma alta dualidade regional: a grande maioria dos estados do Norte e Nordeste migrou para a classe de menor produtividade do trabalho, enquanto que os estados do Sul, Sudeste e Centro-Oeste migraram para as classes de maior produtividade.

\subsection{A produtividade da mão-de-obra setorial nos estados brasileiros: projeções de curto e longo prazo}

A Tabela 3 apresenta a estrutura inicial e final das classes de produtividade estadual da mão-de-obra nos diferentes setores, bem como o tempo necessário para percorrer a metade e o total da distância entre a posição inicial e a de equilíbrio de longo prazo. O método empregado neste trabalho tem a vantagem de possibilitar que se visualize a trajetória da produtividade setorial ao longo do tempo, desde a situação inicial até alcançar a situação de equilíbrio final. Esta trajetória pode ser obtida por meio de alterações no valor de $t$ e verificando as respectivas mudan- 
ças projetadas na estrutura das classes ao longo do tempo. A evolução das trajetórias da produtividade do trabalho setorial entre os estados pode ser vista no conjunto de gráficos apresentados no Anexo B.

A Tabela 3 mostra que quatro setores apresentaram tendência de convergência da produtividade do trabalho entre os estados. São eles: Setores 5, 6, 7 e 8, sendo que este último não apresentou uma convergência plena para uma única classe de produtividade. Desses setores, três mostraram convergência da totalidade dos estados para uma única classe de produtividade: os Setores 5 e 7 convergiram para a classe de menor produtividade e o Setor 6 para a classe de maior produtividade. O Setor 8 mostrou convergência forte para as duas classes de menor produtividade.

A produtividade dos Setores 2, 3 e 4 não apresentou tendência clara de convergência entre os estados. No Setor 2, a produtividade tende a ficar distribuída entre as classes 1, 2 e 3, enquanto que nos Setores 3 e 4, a produtividade tende a ser mais desigual e se fazer presente em todas as classes.

Tabela 3 - Estrutura inicial e final das classes de produtividade setorial do trabalho entre os estados brasileiros, 1990-2000

\begin{tabular}{|c|c|c|c|c|c|c|c|c|c|}
\hline \multirow{2}{*}{ Classes } & \multirow{2}{*}{$\begin{array}{c}\text { Situação } \\
(\%)\end{array}$} & \multicolumn{8}{|c|}{ Setores } \\
\hline & & 1 & 2 & 3 & 4 & 5 & 6 & 7 & 8 \\
\hline \multirow{2}{*}{1} & Inicial & 34,60 & 33,34 & 22,22 & 29,63 & 25,93 & 25,93 & 22,22 & 29,63 \\
\hline & Final & 53,80 & 38,95 & 30,88 & 32,85 & 100 & 0 & 100 & 75,77 \\
\hline \multirow{2}{*}{2} & Inicial & 19,20 & 25,93 & 29,63 & 29,63 & 25,93 & 22,21 & 18,51 & 25,93 \\
\hline & Final & 0 & 22,71 & 32,90 & 8,21 & 0 & 0 & 0 & 20,70 \\
\hline \multirow{2}{*}{3} & Inicial & 23,10 & 22,22 & 22,22 & 22,22 & 22,21 & 25,93 & 25,93 & 22,22 \\
\hline & Final & 11,60 & 38,34 & 12,31 & 46,11 & 0 & 0 & 0 & 3,53 \\
\hline \multirow{2}{*}{4} & Inicial & 23,10 & 18,51 & 25,93 & 18,51 & 25,93 & 25,93 & 33,34 & 22,22 \\
\hline & Final & 34,60 & 0 & 23,91 & 12,83 & 0 & 100 & 0 & 0 \\
\hline \multicolumn{2}{|c|}{ Tempo Dm } & 7 & 28 & 28 & 21 & 13 & 36 & 31 & 10 \\
\hline \multicolumn{2}{|c|}{ Tempo $D t$} & 45 & 270 & 207 & 189 & 153 & 405 & 333 & 99 \\
\hline
\end{tabular}

Fonte: Elaboração dos autores a partir dos Anexos A e C.

Notas: As linhas "Inicial" e "Final" representam, respectivamente, o percentual de estados existentes em cada classe de produtividade na situação inicial e na situação de equilíbrio final; $D m$ e $D t$ indicam, respectivamente, o tempo necessário (em anos) para o setor percorrer a metade e o total da distância entre a situação inicial e a de equilíbrio final. 
Análise da convergência da produtividade da mão-de-obra agropecuária entre os estados brasileiros: aplicação de matrizes de Markov, 1990-2000

Em relação ao Setor 1 (Agropecuária), observa-se que ocorre uma divergência da produtividade entre os estados, pois cresce o número de estados que participam das classes 1 e 4 . Isso significa dizer que os fatos econômicos da década de 90 , especialmente a abertura comercial, ocasionaram um aumento da dualidade da produtividade do trabalho neste setor. Os resultados mostram que esta dualidade tende a se aprofundar nos próximos anos, tendo os estados das regiões Sul, Centro-Oeste e São Paulo como os principais representantes da classe de maior produtividade. O aumento da produtividade nestes estados pode ser atribuído, entre outros fatores, ao aumento da concorrência externa e ao barateamento dos insumos importados, decorrentes da redução de tarifas de importação e da apreciação cambial da primeira fase do Plano Real.

No Setor 5 (Transportes, armazenagem e comunicações), a dinâmica de ajustamento da convergência apresentou um crescimento contínuo de estados na classe de menor produtividade. A classe 2 apresentou um pequeno crescimento no primeiro período e depois passou a apresentar queda contínua de estados participantes. O desempenho global desfavorável da produtividade do trabalho no Setor 5 pode ser atribuído a três fatores principais: a redução de investimentos em infra-estrutura, especialmente na construção e manutenção de estradas; o fraco desempenho das exportações e baixo crescimento econômico verificados no período, visto que, como se trata de um setor "não-transacionável", o mesmo depende muito do desempenho das atividades econômicas domésticas; e a abertura comercial, a qual ocasionou a substituição de produtos domésticos por importados, reduzindo, assim, o transporte e armazenamento de produtos e insumos no mercado doméstico.

O comportamento da produtividade no Setor 8 (Outros serviços coletivos, sociais e pessoais) é similar ao verificado no Setor 5. A única diferença é que a convergência não significou uma migração de todos os estados para a classe de menor produtividade, demonstrando, portanto, um desempenho relativo um pouco melhor. A principal explicação para o fraco desempenho deste setor também está no fato de ser um "não-transacionável” e, portanto, prejudicado pelo pequeno crescimento econômico e pelo fraco desempenho das exportações verificados na década de 90 . 
Em relação ao Setor 7 (Administração pública, defesa e seguridade social), observa-se um crescimento contínuo da migração de estados para a classe de menor produtividade. A diferença que pode ser destacada em relação a este setor é que, na situação inicial, ele apresentava uma participação relativamente maior de estados na classe de elevada produtividade. $\mathrm{O}$ fraco desempenho da produtividade do trabalho neste setor pode ser atribuído aos seguintes fatores interligados: redução do nível de atividade do setor público na economia, ocorrida por causa do processo de privatização de empresas públicas, extinção de órgãos públicos e concessão de serviços públicos à iniciativa privada; queda da remuneração média dos servidores públicos; crise fiscal e o conseqüente sucateamento da infra-estrutura pública; e aumento (ou manutenção) do nível de emprego no setor.

O Setor 6 (Intermediação financeira, atividades imobiliárias, aluguéis, serviços prestados às empresas, saúde e educação mercantis e serviços domésticos) apresenta uma convergência da totalidade dos estados brasileiros para a classe de nível de produtividade mais alta. O processo de ajustamento mostra uma contínua migração de estados para a classe de maior produtividade. A automação do sistema financeiro, com a conseqüente redução no nível de emprego, ocorrida durante a década de noventa, colaboraram para o aumento da produtividade da mão-de-obra neste setor.

Além da automação, este setor foi beneficiado por uma série de fatos políticos e econômicos. Entre eles, pode-se destacar: a política monetária de taxa de juros elevada, adotada a partir do Plano Real; o crescimento da necessidade de financiamento do setor público; menor regulação do mercado de capitais; abertura do setor ao exterior, possibilitando a ocorrência de fusões e aquisições de instituições financeiras domésticas com instituições internacionais; e adoção, por parte do governo, de ações visando a reestruturação e o saneamento de instituições financeiras domésticas.

Em relação aos setores que não apresentaram tendência clara de convergência, pode-se destacar alguns fatos. No Setor 2 (Indústria extrativa mineral, indústria de transformação, eletricidade, gás e água), deixa de existir a classe de maior produtividade, mas aumenta bastante o número de estados que migram para a classe 3 . Neste setor, observa- 
se, como já visto no Setor 1, uma dualidade da produtividade, que se perpetua pela manutenção das classes de produtividade 1 e 3 . Neste caso, os estados que representam a classe de maior produtividade são basicamente os da região Sul, Sudeste, alguns estados do Nordeste, especialmente a Bahia, e do Norte, o Amazonas.

No Setor 3 (Construção civil), observa-se um crescimento contínuo da migração de estados para as duas classes de menor produtividade e uma saída contínua de estados da classe 3 . Em relação à classe de maior produtividade, ocorre um aumento da participação no primeiro período e passa a diminuir continuamente a participação nos períodos posteriores. Essas alterações são muito lentas e todas as classes mantêm um número não desprezível de estados abrigados, demonstrando a perpetuação de uma situação de alta segmentação da produtividade do trabalho no setor.

O Setor 4 (Comércio e reparação de veículos, de objetos pessoais e de uso doméstico, alojamento e alimentação) apresenta uma grande migração de estados da classe 2 para a 3 , um pequeno aumento de estados na classe 1 nos três primeiros períodos, quando começam a sair em direção às classes de maior produtividade. Com base nestas informações, pode-se dizer que a situação deste setor passa a ser mais favorável à medida que o tempo passa, especialmente a partir do terceiro período.

A análise da trajetória deste setor indica que, embora a situação no longo prazo seja mais promissora, o efeito imediato do desempenho econômico da última década foi bastante desfavorável. A principal explicação que se pode dar para este fraco desempenho da produtividade setorial é o baixo nível de demanda verificado no período e, ligado a isso, o baixo custo relativo da mão-de-obra, o que inibe a substituição do fator trabalho por capital.

\section{Conclusões}

O objetivo deste estudo foi analisar a convergência da produtividade da mão-de-obra agrícola entre os estados brasileiros na década de noventa e a projeção do comportamento da mesma no curto e longo prazo. Os dados relativos à década de 90, que definiram a matriz de transição, revelaram alguns aspectos relevantes. Primeiro, houve 
um pequeno aumento da produtividade da mão-de-obra no conjunto dos estados brasileiros. Além da Agropecuária, contribuíram para este aumento de produtividade os Setores 6, 2 e 4. Segundo, houve uma concentração do aumento da produtividade em alguns estados, especialmente do Sudeste, Sul e Centro-Oeste, e em alguns setores, principalmente no Setor 6 .

Esses dois aspectos combinados indicam que no futuro haverá um aprofundamento das disparidades regionais em termos de produtividade da mão-de-obra. As projeções para as próximas décadas e para o longo prazo mostram essa tendência ao revelarem que, apesar do aumento de produtividade global, em $50 \%$ dos setores analisados ocorre um aumento do número de estados participantes nas classes de menor produtividade do trabalho.

Com as projeções de curto e longo prazo, obtidas pelo método de Markov, pode-se dizer que há uma tendência de formação de dois clubes de convergência na Agropecuária. O primeiro, convergindo para a classe de menor produtividade, é formado principalmente pelos estados do Norte e Nordeste. O segundo, convergindo para as duas classes de maior produtividade, é formado principalmente pelos estados do Sudeste, Sul e Centro-Oeste. Além disso, entre os oito setores analisados, o setor agropecuário é o que mostrou maior velocidade de convergência.

Em relação aos demais setores analisados, em linhas gerais, pode-se dizer que houve convergência plena, ou seja, para uma única classe de produtividade em três setores (Setores 5, 6 e 7); tendência de convergência para mais de uma classe de produtividade (classes contíguas) em um setor (Setor 8); e ausência de convergência nos demais três setores (Setores 2, 3 e 4). O processo de convergência nestes setores apresentou-se relativamente mais lento que o da agropecuária, sendo que os Setores 8 e 5 foram os que demonstraram maior velocidade.

Enfim, pode-se dizer que as condições econômicas prevalecentes na década de noventa não favoreceram a convergência da produtividade da mão-de-obra no setor agrícola. Pelo contrário, elas aumentaram a disparidade da mesma entre os estados de modo a projetar o surgimento de dois clubes, um de baixa e outro de alta produtividade, no longo 
prazo. Para o conjunto dos demais setores, também se pode dizer que as condições econômicas da década de 90 não favoreceram a convergência, apesar de ela ter ocorrido em três setores.

\section{Referências bibliográficas}

BARRO, R.J.; SALA-I-MARTIN, X. Convergence across States and Regions. Brookings Papers on Economic Activity, 1991, p.107-182.

BARRO, R.J.; SALA-I-MARTIN, X. Convergence. Journal of Political Economy. 100, 1992, p.223-251.

BARRO, R.J.; SALA-I-MARTIN, X. Economic Growth Theory, MIT Press, 1995.

BAUMONT, C.; ERTUR, C. E LE GALLO, J. Convergence des régions européenes: une approche par l'économétrie spatiale. LATEC, Université de Bourgogne, Fev. 2000.

BAUMOL, W.J. Productivity growth, convergence, and welfare: what the long-run data how. American Economic Review, 54, 1986, p.10721085 .

BERNARD, A.B. E DURLAUF, S.N.1 Convergence in International Output. Journal of Applied Econometrics, 10, 1995, p.97-108.

Bernard, A.B.; DURLAUF, S.N. Interpreting Tests of the Convergence Hypothesis, Journal of Econometrics, 71, 1996, p.161-173.

FERREIRA, A.H.B. Concentração regional e dispersão das rendas per capita estaduais: um comentário. Belo Horizonte: UFMG/Cedeplar, 1998 (Texto para discussão, 121).

FINGLETON, B. Estimates of time to economic convergence: an analysis of regions of the European Union. International Regional Science Review, 22, 1999, p.5-35.

FOCHEZATTO, A.; SOUZA, N.J. Estabilização e reformas estruturais no Brasil após o Plano Real: uma análise de equilíbrio geral computável. Pesquisa e Planejamento Econômico, v. 30, n. 3, dez 2000, p. 395-426. 
FRIEDMAN M. Do old fallacies ever die?, Journal of Economic Literature, 30, 1992, p.2129-132.

HÉNIN P.-Y.; LE PEN, Y. Les épisodes de la convergence européenne, Revue Economique, 46, 1995, p.667-677.

INSTITUTO BRASILEIRO DE GEOGRAFIA E ESTATÍSTICA. Contas regionais - 2000. Rio de Janeiro: IBGE, 1997.

INSTITUTO BRASILEIRO DE GEOGRAFIA E ESTATÍSTICA. Censos Demográficos de 1991 e 2000. Rio de Janeiro: IBGE, 1997.

JEAN-PIERRE P. La convergence régionale européenne: une approche empirique par les clubs et les panels, Revue d'Economie Régionale et Urbaine, 1, 1999, p.21-44.

LE GALLO, J. Space-time analysis of GDP disparities among European regions: A Markov chains approach. Dijon/França: University of Burgundy, Março 2001.

MAGRINI, S. The evolution of income disparities among the regions of the European Union. Regional Science and Urban Economics, № 29, 1999.

MANKIW N.G.; ROMER D.; WEIL, e D.N. A Contribution to the Empirics of Economic Growth, Quarterly Journal of Economics, 57, 1992, p.407-437.

MUENDLER, M. Trade, technology, and productivity: a study of Brazilian manufacturers, 1986-1998. Berkeley: University of California, 2001.

PAGAN, A.; Ullah, A. Nonparametric Econometrics. Cambridge/UK: Cambridge University Press,1999.

PINHEIRO, A. C.; GIAMBIAGI, F.; MOREIRA, M. M. O Brasil na década de 90: uma transição bem-sucedida? Rio de Janeiro: BNDES, Departamento Econômico - DEPEC, 2001. 36p. (Textos para discussão, n. 91)

QUAH D. Galton's Fallacy and Tests of the Convergence Hypothesis, The Scandinavian Journal of Economics, 95, 1993, p.427-443. 
QUAH D. Empirical cross-section dynamics in economic growth, European Economic Review, 37, 1993a, p.426-434.

QUAH D. Galton's fallacy and tests of the convergence hypothesis, Scandinavian Journal of Economics, 95, 1993b, p.427-443.

REY S.J.; MONTOURI, B.D. U.S. Regional Income Convergence: a Spatial Econometric Perspective, Regional Studies, 33, 1999, p.145-156.

SIEGEL, S. Nonparametric Statistics for the Behavioral Sciences. Nova Iorque: McGraw-Hill Book Company, 1956.

SIMON, C.P. ; BLUME, L. Matemática para Economistas. Artmed Editora S. A. Porto Alegre. 2004.

SOLOW R.M. A. Contribution to the Theory of Economic Growth, Quarterly Journal of Economics, 70, 1956, p.65-94.

STÜLP, V.J.; FOCHEZATTO, A. A evolução das disparidades regionais no Rio Grande do Sul: uma aplicação de matrizes de Markov. Nova Economia

SWAN T.W. Economic Growth and Capital Accumulation, Economic Record, 32, 1956, p.334-361.

VALDÉS, B. Economic Growth: theory, empirics and policy. Edward Elgar Publishing, 1999. 
Anexo A: Solução do sistema de equações de diferenças dos setores.

\begin{tabular}{|c|c|c|c|c|c|c|c|c|c|}
\hline \multicolumn{10}{|c|}{ Setor 1} \\
\hline $\left.\begin{array}{l}F 1 t \\
F 2 t \\
F 3 t \\
F 4 t\end{array}\right]$ & $=\left[\begin{array}{l}1 \\
0 \\
0 \\
0\end{array}\right]_{(1)}$ & $+\left[\begin{array}{c}-c \\
0,\end{array}\right.$ & $\left.\begin{array}{c}0,192 \\
, 192 \\
0 \\
0\end{array}\right]$ & $(0,4)$ & )$^{t}+\left[\begin{array}{r}0, \\
-0\end{array}\right.$ & $\left.\begin{array}{c}0 \\
0 \\
, 116 \\
0,116\end{array}\right]_{(0,3}$ & $, 333)^{t}+\left[\begin{array}{l}0, \\
0,\end{array}\right.$ & $\left.\begin{array}{c}0 \\
0 \\
0,25 \\
0,75\end{array}\right](1)^{t}$ & \\
\hline \multicolumn{10}{|c|}{ Setor 2} \\
\hline $\left.\begin{array}{l}F 1 t \\
F 2 t \\
F 3 t \\
F 4 t\end{array}\right]$ & $=\left[\begin{array}{c}0,390 \\
0,227 \\
0,383 \\
0\end{array}\right.$ & $\left.\begin{array}{l}0 \\
7 \\
3\end{array}\right](1)^{t}+$ & $+\left[\begin{array}{r}-1, \\
-0, \\
1,1 \\
1\end{array}\right.$ & $\begin{array}{l}053 \\
245 \\
14\end{array}$ & $(0,8)^{t}+$ & {$\left[\begin{array}{c}1,045 \\
0,210 \\
-1,255 \\
0\end{array}\right]$} & $\int(0,782)^{t}+$ & $+\left[\begin{array}{c}-0,047 \\
0,067 \\
-0,020 \\
0\end{array}\right]$ & $(-0,143)^{t}$ \\
\hline \multicolumn{10}{|c|}{ Setor 3} \\
\hline$\left[\begin{array}{l}F 1 t \\
F 2 t \\
F 3 t \\
F 4 t\end{array}\right]$ & $=\left[\begin{array}{l}0,309 \\
0,329 \\
0,123 \\
0,239\end{array}\right.$ & $\left.\begin{array}{l}9 \\
9 \\
3 \\
9\end{array}\right](1)^{t}+$ & {$\left[\begin{array}{r}-0, \\
-0,0 \\
0,0 \\
0,0\end{array}\right.$} & $\left.\begin{array}{l}53 \\
58 \\
45 \\
66\end{array}\right]$ & $(0,8)^{t}+$ & {$\left[\begin{array}{c}-0,024 \\
0,034 \\
-0,007 \\
-0,003\end{array}\right.$} & $7(0,358)^{t}+$ & $+\left[\begin{array}{c}-0,010 \\
-0,009 \\
0,062 \\
-0,042\end{array}\right]$ & ]$_{(-0,128)^{t}}$ \\
\hline \multicolumn{10}{|c|}{ Setor 4} \\
\hline$\left[\begin{array}{l}F 1 t \\
F 2 t \\
F 3 t \\
F 4 t\end{array}\right]$ & {$\left[\begin{array}{l}0,329 \\
0,082 \\
0,461 \\
0,128\end{array}\right]$} & $(1)^{t}+$ & {$\left[\begin{array}{r}0,41 \\
-0,10 \\
-0,20 \\
-0,0\end{array}\right.$} & & $0,744)^{t}+$ & {$\left[\begin{array}{c}-5,814 \\
5,814 \\
0 \\
0\end{array}\right]$} & $(0,375)^{t}+$ & $+\left[\begin{array}{c}5,372 \\
-5,494 \\
-0,033 \\
0,155\end{array}\right]$ & $(0,363)^{t}$ \\
\hline
\end{tabular}




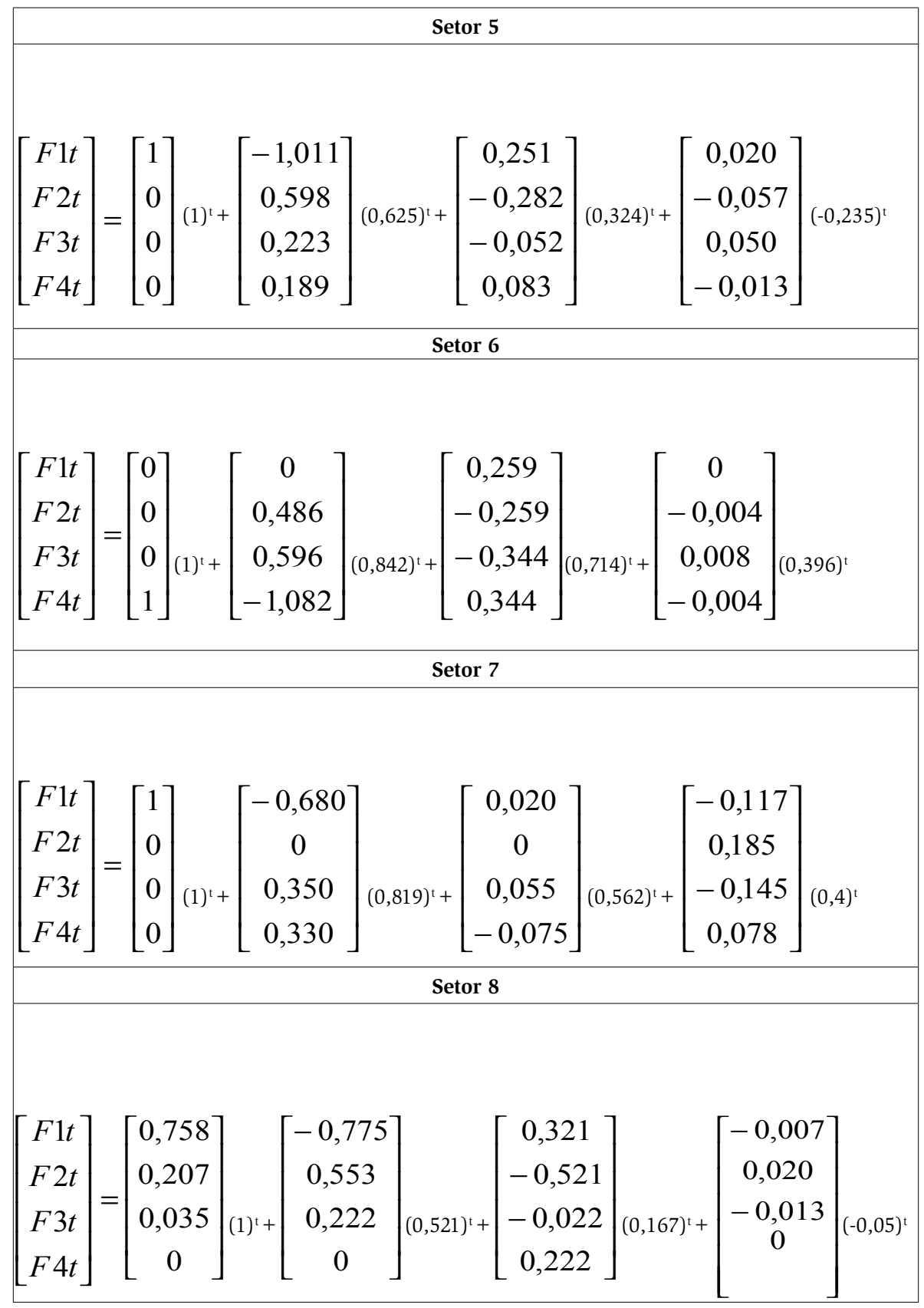

Fonte: Elaboração dos autores. 
Anexo B: Participação dos estados nas classes de produtividade da mão-deobra setorial nos onze primeiros períodos de ajustamento.
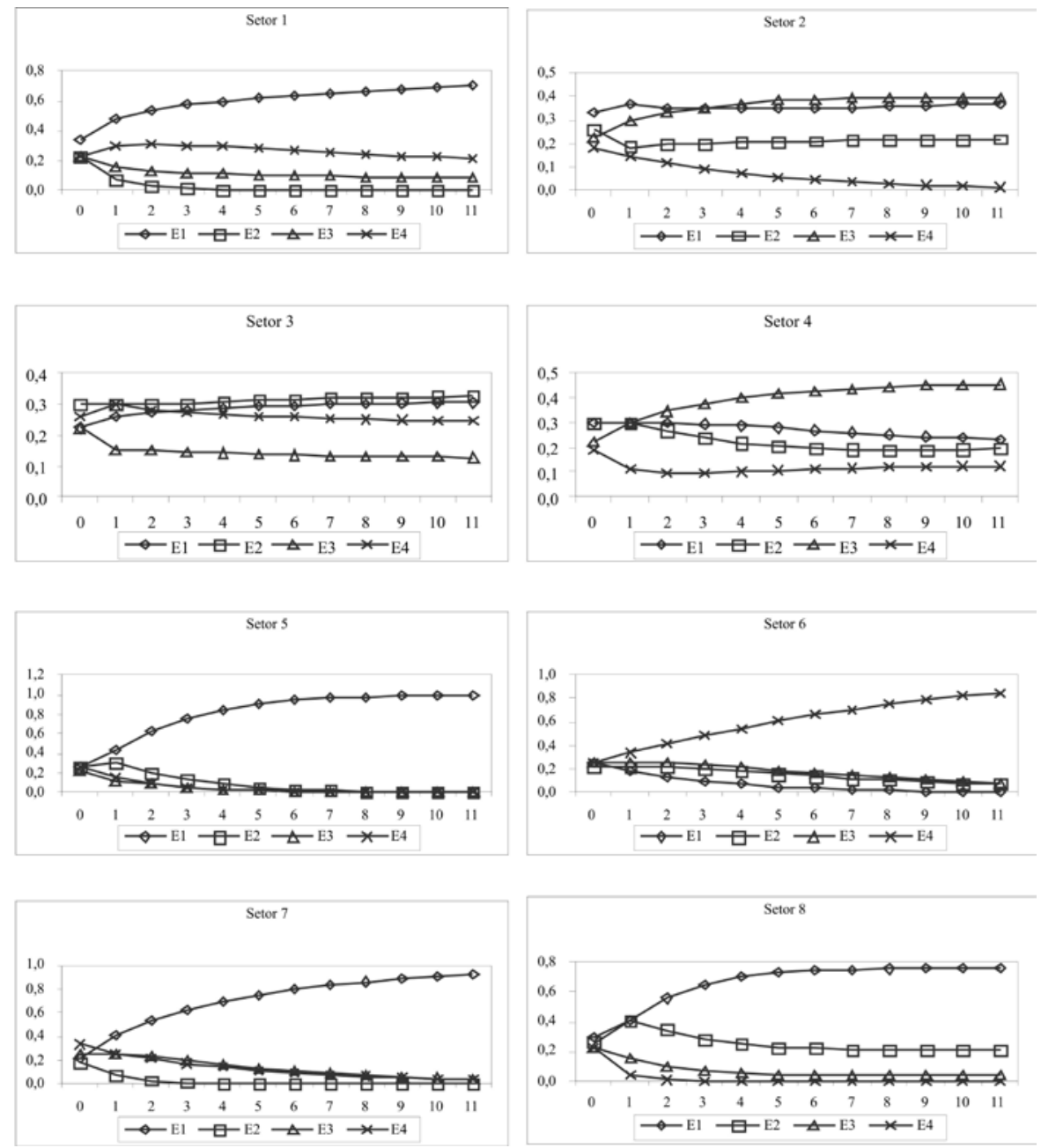

Fonte: Elaboração dos autores.

Notas: no eixo horizontal estão os períodos de 9 anos, no eixo vertical está a participação dos estados nas classes E1, E2, E3 e E4 de produtividade da mão-de-obra. 
Anexo C - Distribuição dos estados brasileiros quanto à sua produtividade do trabalho setorial, 1990/1991 e 1999/2000.

\begin{tabular}{|c|c|c|c|c|c|c|c|c|}
\hline \multirow{2}{*}{ Classes } & \multicolumn{2}{|c|}{ Setor 1} & \multicolumn{2}{|c|}{ Setor 2} & \multicolumn{2}{|c|}{ Setor 3} & \multicolumn{2}{|c|}{ Setor 4} \\
\hline & $90 / 91$ & 99/00 & $90 / 91$ & $99 / 00$ & $90 / 91$ & $99 / 00$ & $90 / 91$ & 99/00 \\
\hline 1 & $\begin{array}{l}\text { PI }(0,21) \\
\text { AC }(0,28) \\
\text { MA }(0,30) \\
\text { TO }(0,38) \\
\operatorname{RR}(0,43) \\
\operatorname{RN}(0,44) \\
\text { CE }(0,47) \\
\operatorname{PB}(0,48) \\
\operatorname{BA}(0,49)\end{array}$ & $\begin{array}{l}\mathrm{RN}(0,20) \\
\operatorname{PI}(0,20) \\
\mathrm{AC}(0,24) \\
\mathrm{CE}(0,25) \\
\mathrm{MA}(0,26) \\
\mathrm{RR}(0,28) \\
\mathrm{AM}(0,28) \\
\mathrm{AL}(0,30) \\
\mathrm{SE}(0,42) \\
\operatorname{PB}(0,43) \\
\mathrm{TO}(0,46) \\
\operatorname{BA}(0,47) \\
\operatorname{PE}(0,50)\end{array}$ & $\begin{array}{l}\operatorname{RR}(0,07) \\
\operatorname{TO}(0,13) \\
\operatorname{AP}(0,23) \\
\operatorname{MT}(0,24) \\
\operatorname{RO}(0,24) \\
\mathrm{MA}(0,33) \\
\operatorname{MS}(0,35) \\
\operatorname{PI}(0,37) \\
\operatorname{PB}(0,38)\end{array}$ & $\begin{array}{l}\mathrm{RR}(0,18) \\
\mathrm{TO}(0,19) \\
\mathrm{PI}(0,24) \\
\mathrm{AP}(0,26) \\
\operatorname{RO}(0,30) \\
\mathrm{MA}(0,33) \\
\mathrm{AC}(0,35) \\
\mathrm{CE}(0,36) \\
\mathrm{GO}(0,40) \\
\operatorname{PA}(0,40)\end{array}$ & $\begin{array}{l}\mathrm{TO}(0,01) \\
\operatorname{PI}(0,28) \\
\mathrm{AP}(0,34) \\
\mathrm{MA}(0,34) \\
\mathrm{GO}(0,57) \\
\operatorname{MT}(0,60)\end{array}$ & $\begin{array}{l}\mathrm{TO}(0,21) \\
\mathrm{AP}(0,22) \\
\mathrm{MA}(0,32) \\
\operatorname{RR}(0,35) \\
\operatorname{PI}(0,50) \\
\operatorname{SE}(0,53) \\
\operatorname{PB}(0,64)\end{array}$ & $\begin{array}{l}\mathrm{CE}(0,52) \\
\operatorname{PB}(0,53) \\
\operatorname{PI}(0,53) \\
\mathrm{MA}(0,56) \\
\mathrm{RN}(0,59) \\
\operatorname{PA}(0,61) \\
\mathrm{MS}(0,61) \\
\mathrm{TO}(0,63)\end{array}$ & $\begin{array}{l}\operatorname{PI}(0,31) \\
\text { MA }(0,38) \\
\operatorname{PB}(0,41) \\
\operatorname{RN}(0,42) \\
\operatorname{PA}(0,42) \\
\text { TO }(0,44) \\
\text { SE }(0,56) \\
\text { CE }(0,57) \\
\text { AL }(0,59) \\
\operatorname{GO}(0,59) \\
\text { AC }(0,63)\end{array}$ \\
\hline 2 & $\begin{array}{l}\operatorname{PE}(0,59) \\
\operatorname{AL}(0,60) \\
\operatorname{ES}(0,60) \\
\operatorname{SE}(0,61) \\
\operatorname{RO}(0,63)\end{array}$ & $\begin{array}{l}\mathrm{ES}(0,72) \\
\mathrm{RO}(0,73)\end{array}$ & $\begin{array}{l}\operatorname{AC}(0,43) \\
\mathrm{CE}(0,44) \\
\operatorname{PA}(0,46) \\
\mathrm{GO}(0,47) \\
\operatorname{AL}(0,49) \\
\operatorname{RN}(0,50) \\
\operatorname{DF}(0,52)\end{array}$ & $\begin{array}{l}\operatorname{MT}(0,41) \\
\operatorname{PB}(0,43) \\
\operatorname{MS}(0,55) \\
\operatorname{PE}(0,56) \\
\operatorname{DF}(0,57)\end{array}$ & $\begin{array}{l}\mathrm{PB}(0,70) \\
\mathrm{SC}(0,71) \\
\operatorname{AL}(0,73) \\
\operatorname{RR}(0,75) \\
\operatorname{BA}(0,76) \\
\operatorname{MS}(0,86) \\
\mathrm{CE}(0,88) \\
\operatorname{AC}(0,88)\end{array}$ & $\begin{array}{l}\operatorname{MT}(0,68) \\
\operatorname{GO}(0,68) \\
\operatorname{AL}(0,72) \\
\operatorname{RS}(0,74) \\
\operatorname{AC}(0,78) \\
\operatorname{BA}(0,79) \\
\operatorname{SC}(0,84) \\
\operatorname{MS}(0,86)\end{array}$ & $\begin{array}{l}\mathrm{SE}(0,76) \\
\mathrm{GO}(0,78) \\
\operatorname{AL}(0,81) \\
\operatorname{PR}(0,82) \\
\mathrm{AC}(0,84) \\
\operatorname{RO}(0,86) \\
\mathrm{BA}(0,88) \\
\operatorname{PE}(0,90)\end{array}$ & $\begin{array}{l}\mathrm{RO}(0,75) \\
\mathrm{BA}(0,77) \\
\mathrm{DF}(0,85) \\
\operatorname{RR}(0,87) \\
\operatorname{PR}(0,92)\end{array}$ \\
\hline 3 & $\begin{array}{l}\operatorname{MT}(0,85) \\
\operatorname{AM}(0,87) \\
\operatorname{RJ}(0,94) \\
\operatorname{PR}(0,97) \\
\operatorname{MG}(1,03) \\
\operatorname{GO}(1,09) \\
\operatorname{AP}(1,12)\end{array}$ & $\begin{array}{l}\operatorname{MG}(0,92) \\
\operatorname{AP}(0,94) \\
\operatorname{RJ}(0,95) \\
\operatorname{PA}(1,10)\end{array}$ & $\begin{array}{l}\text { PE }(0,65) \\
\text { SC }(0,85) \\
\text { MG }(0,87) \\
\operatorname{RS}(1,03) \\
\text { SE }(1,04) \\
\text { ES }(1,05)\end{array}$ & $\begin{array}{l}\operatorname{AL}(0,61) \\
\operatorname{RN}(0,67) \\
\operatorname{SC}(0,83) \\
\operatorname{SE}(0,85) \\
\text { MG }(0,88) \\
\operatorname{PR}(0,89) \\
\operatorname{ES}(0,91) \\
\operatorname{RS}(1,00)\end{array}$ & $\begin{array}{l}\mathrm{RN}(0,93) \\
\mathrm{SE}(0,96) \\
\operatorname{PE}(0,97) \\
\mathrm{MG}(1,01) \\
\operatorname{RS}(1,01) \\
\mathrm{ES}(1,04)\end{array}$ & $\begin{array}{l}\operatorname{PA}(0,93) \\
\mathrm{DF}(0,96) \\
\mathrm{RJ}(1,05) \\
\mathrm{RN}(1,05)\end{array}$ & $\begin{array}{l}\text { MG }(1,05) \\
\text { MT( } 1,07) \\
\text { ES }(1,10) \\
\text { SC }(1,13) \\
\text { SP }(1,15) \\
\operatorname{RJ}(1,19)\end{array}$ & $\begin{array}{l}\text { MG }(0,98) \\
\operatorname{RJ}(0,99) \\
\operatorname{MS}(1,02) \\
\operatorname{PE}(1,02) \\
\operatorname{AM}(1,03) \\
\operatorname{SC}(1,07) \\
\operatorname{ES}(1,11) \\
\text { MT }(1,13)\end{array}$ \\
\hline 4 & $\begin{array}{l}\mathrm{SC}(1,43) \\
\mathrm{RS}(1,55) \\
\mathrm{PA}(2,01) \\
\mathrm{MS}(2,49) \\
\mathrm{SP}(2,54) \\
\mathrm{DF}(3,05)\end{array}$ & $\begin{array}{l}\mathrm{DF}(1,46) \\
\mathrm{GO}(1,57) \\
\operatorname{PR}(1,67) \\
\mathrm{RS}(1,71) \\
\mathrm{SC}(1,75) \\
\mathrm{MT}(1,93) \\
\mathrm{SP}(2,68) \\
\operatorname{MS}(2,99)\end{array}$ & $\begin{array}{l}\mathrm{BA}(1,07) \\
\mathrm{RJ}(1,16) \\
\mathrm{SP}(1,20) \\
\operatorname{PR}(1,28) \\
\mathrm{AM}(2,32)\end{array}$ & $\begin{array}{l}\mathrm{BA}(1,09) \\
\mathrm{SP}(1,19) \\
\operatorname{RJ}(2,07) \\
\operatorname{AM}(2,32)\end{array}$ & $\begin{array}{l}\operatorname{SP}(1,13) \\
\operatorname{RJ}(1,15) \\
\mathrm{DF}(1,15) \\
\operatorname{PA}(1,25) \\
\operatorname{PR}(1,34) \\
\operatorname{RO}(1,50) \\
\operatorname{AM}(1,72)\end{array}$ & $\begin{array}{l}\operatorname{ES}(1,10) \\
\operatorname{SP}(1,14) \\
\mathrm{MG}(1,15) \\
\mathrm{CE}(1,18) \\
\operatorname{PE}(1,19) \\
\operatorname{RO}(1,28) \\
\operatorname{PR}(1,31) \\
\operatorname{AM}(1,55)\end{array}$ & $\begin{array}{l}\operatorname{RS}(1,24) \\
\operatorname{DF}(1,41) \\
\operatorname{AM}(1,45) \\
\operatorname{RR}(1,67) \\
\operatorname{AP}(2,90)\end{array}$ & $\begin{array}{l}\operatorname{SP}(1,35) \\
\operatorname{RS}(1,48) \\
\operatorname{AP}(2,09)\end{array}$ \\
\hline
\end{tabular}




\section{Continuação Anexo C}

\begin{tabular}{|c|c|c|c|c|c|c|c|c|}
\hline \multirow{2}{*}{ Classes } & \multicolumn{2}{|c|}{ Setor 5} & \multicolumn{2}{|c|}{ Setor 6} & \multicolumn{2}{|c|}{ Setor 7} & \multicolumn{2}{|c|}{ Setor 8} \\
\hline & $90 / 91$ & $99 / 00$ & $90 / 91$ & $99 / 00$ & $90 / 91$ & $99 / 00$ & $90 / 91$ & $99 / 00$ \\
\hline 1 & $\begin{array}{l}\operatorname{AL}(0,54) \\
\operatorname{CE}(0,62) \\
\operatorname{PE}(0,64) \\
\operatorname{PI}(0,64) \\
\operatorname{RO}(0,65) \\
\operatorname{PA}(0,70) \\
\operatorname{PB}(0,71)\end{array}$ & $\begin{array}{l}\operatorname{PA}(0,53) \\
\operatorname{PI}(0,56) \\
\operatorname{PB}(0,56) \\
\operatorname{AL}(0,59) \\
\operatorname{SE}(0,59) \\
\operatorname{RR}(0,60) \\
\operatorname{GO}(0,66) \\
\mathrm{CE}(0,66) \\
\mathrm{TO}(0,66) \\
\operatorname{RO}(0,68) \\
\operatorname{RN}(0,72) \\
\operatorname{PE}(0,73)\end{array}$ & $\begin{array}{l}\operatorname{PI}(0,25) \\
\operatorname{PB}(0,29) \\
\operatorname{TO}(0,32) \\
\operatorname{RN}(0,33) \\
\operatorname{AC}(0,34) \\
\operatorname{SE}(0,35) \\
\operatorname{MA}(0,36)\end{array}$ & $\begin{array}{l}\mathrm{MA}(0,29) \\
\mathrm{TO}(0,30) \\
\mathrm{AC}(0,33) \\
\mathrm{PI}(0,35) \\
\operatorname{PB}(0,38)\end{array}$ & $\begin{array}{l}\mathrm{TO}(0,52) \\
\operatorname{PI}(0,56) \\
\mathrm{AL}(0,57) \\
\mathrm{MA}(0,60) \\
\operatorname{PB}(0,61) \\
\mathrm{MS}(0,64)\end{array}$ & $\begin{array}{l}\text { TO }(0,38) \\
\operatorname{RR}(0,42) \\
\operatorname{PI}(0,53) \\
\text { GO }(0,56) \\
\operatorname{MA}(0,57) \\
\operatorname{BA}(0,59) \\
\operatorname{PB}(0,60) \\
\operatorname{AL}(0,61) \\
\operatorname{MS}(0,63) \\
\operatorname{PA}(0,64) \\
\operatorname{AM}(0,64)\end{array}$ & $\begin{array}{l}\mathrm{DF}(0,13) \\
\mathrm{RN}(0,22) \\
\mathrm{CE}(0,52) \\
\mathrm{SP}(0,61) \\
\mathrm{PI}(0,64) \\
\mathrm{MA}(0,66) \\
\operatorname{PR}(0,67) \\
\operatorname{PB}(0,70)\end{array}$ & $\begin{array}{l}\mathrm{RN}(0,17) \\
\mathrm{DF}(0,24) \\
\mathrm{PI}(0,32) \\
\mathrm{MA}(0,36) \\
\mathrm{CE}(0,42) \\
\mathrm{PB}(0,42) \\
\mathrm{SE}(0,51) \\
\mathrm{SC}(0,58) \\
\operatorname{PR}(0,59) \\
\mathrm{TO}(0,64) \\
\operatorname{AL}(0,66)\end{array}$ \\
\hline 2 & $\begin{array}{l}\mathrm{GO}(0,77) \\
\mathrm{SE}(0,77) \\
\mathrm{AC}(0,79) \\
\mathrm{BA}(0,81) \\
\mathrm{RN}(0,86) \\
\operatorname{RR}(0,89) \\
\operatorname{MG}(0,92)\end{array}$ & $\begin{array}{l}\text { MA }(0,75) \\
\operatorname{BA}(0,76) \\
\operatorname{AC}(0,79) \\
\operatorname{SC}(0,81) \\
\text { MT }(0,81) \\
\operatorname{RS}(0,88) \\
\operatorname{PR}(0,94) \\
\text { AM }(0,95)\end{array}$ & $\begin{array}{l}\text { AL }(0,41) \\
\operatorname{RO}(0,42) \\
\operatorname{CE}(0,43) \\
\text { GO }(0,46) \\
\operatorname{RR}(0,46) \\
\operatorname{PA}(0,47)\end{array}$ & $\begin{array}{l}\operatorname{RR}(0,39) \\
\operatorname{AP}(0,41) \\
\operatorname{GO}(0,43) \\
\mathrm{CE}(0,44) \\
\mathrm{SE}(0,44) \\
\operatorname{AL}(0,48)\end{array}$ & $\begin{array}{l}\operatorname{PE}(0,68) \\
\mathrm{GO}(0,69) \\
\mathrm{SE}(0,69) \\
\operatorname{RN}(0,69) \\
\operatorname{BA}(0,70)\end{array}$ & $\begin{array}{l}\mathrm{RN}(0,67) \\
\mathrm{SE}(0,68)\end{array}$ & $\begin{array}{l}\operatorname{MG}(0,84) \\
\operatorname{RS}(0,87) \\
\operatorname{SE}(0,96) \\
\operatorname{SC}(1,01) \\
\operatorname{AL}(1,22) \\
\operatorname{ES}(1,25) \\
\operatorname{MT}(1,29)\end{array}$ & $\begin{array}{l}\text { SP }(0,91) \\
\operatorname{PA}(0,92) \\
\operatorname{RS}(0,93) \\
\text { MG }(0,97) \\
\text { MT }(1,11) \\
\operatorname{PE}(1,11) \\
\text { AC }(1,16) \\
\text { BA }(1,24) \\
\text { RO }(1,36) \\
\text { MS }(1,38) \\
\text { AP }(1,39)\end{array}$ \\
\hline 3 & $\begin{array}{l}\text { SP }(1,00) \\
\text { MT }(1,01) \\
\text { SC }(1,04) \\
\operatorname{RS}(1,05) \\
\text { TO }(1,10) \\
\operatorname{PR}(1,15)\end{array}$ & $\begin{array}{l}\mathrm{MG}(0,98) \\
\mathrm{MS}(1,05) \\
\operatorname{AP}(1,09)\end{array}$ & $\begin{array}{l}\operatorname{ES}(0,50) \\
\operatorname{AP}(0,51) \\
\operatorname{MS}(0,55) \\
\operatorname{PE}(0,57) \\
\operatorname{MT}(0,57) \\
\operatorname{MG}(0,64) \\
\operatorname{BA}(0,64)\end{array}$ & $\begin{array}{l}\operatorname{PA}(0,49) \\
\operatorname{MS}(0,50) \\
\operatorname{RN}(0,50) \\
\operatorname{MT}(0,50) \\
\operatorname{RO}(0,54) \\
\operatorname{PE}(0,55) \\
\operatorname{BA}(0,58)\end{array}$ & $\begin{array}{l}\operatorname{CE}(0,73) \\
\operatorname{AC}(0,74) \\
\operatorname{PA}(0,78) \\
\operatorname{PR}(0,80) \\
\operatorname{ES}(0,86) \\
\operatorname{MT}(0,86) \\
\operatorname{RO}(0,86)\end{array}$ & $\begin{array}{l}\operatorname{AP}(0,75) \\
\operatorname{CE}(0,81) \\
\operatorname{PR}(0,81) \\
\operatorname{PE}(0,81) \\
\operatorname{AC}(0,83) \\
\operatorname{RO}(0,85) \\
\operatorname{ES}(0,89)\end{array}$ & $\begin{array}{l}\mathrm{BA}(1,65) \\
\mathrm{RJ}(1,69) \\
\mathrm{MS}(1,70) \\
\mathrm{PA}(1,74) \\
\mathrm{TO}(1,79) \\
\mathrm{AC}(1,80)\end{array}$ & $\begin{array}{l}\mathrm{GO}(1,51) \\
\mathrm{RJ}(1,56) \\
\mathrm{ES}(1,58) \\
\mathrm{RR}(1,75)\end{array}$ \\
\hline 4 & $\begin{array}{l}\operatorname{AM}(1,19) \\
\operatorname{MA}(1,20) \\
\operatorname{AP}(1,22) \\
\operatorname{RJ}(1,24) \\
\operatorname{MS}(1,27) \\
\operatorname{ES}(1,53) \\
\operatorname{DF}(1,78)\end{array}$ & $\begin{array}{l}\text { RJ }(1,17) \\
\text { SP }(1,24) \\
\text { ES }(1,73) \\
\text { DF }(1,85)\end{array}$ & $\begin{array}{l}\operatorname{AM}(, 79) \\
\operatorname{RS}(0,79) \\
\operatorname{SC}(0,83) \\
\operatorname{PR}(0,84) \\
\operatorname{RJ}(1,02) \\
\operatorname{SP}(1,48) \\
\operatorname{DF}(7,59)\end{array}$ & $\begin{array}{l}\operatorname{MG}(0,72) \\
\operatorname{ES}(0,77) \\
\operatorname{SC}(0,84) \\
\operatorname{AM}(0,85) \\
\operatorname{PR}(1,02) \\
\operatorname{RS}(1,08) \\
\operatorname{RJ}(1,11) \\
\operatorname{SP}(1,60) \\
\operatorname{DF}(2,21)\end{array}$ & $\begin{array}{l}\operatorname{AM}(0,94) \\
\operatorname{AP}(0,94) \\
\operatorname{MG}(0,94) \\
\operatorname{RS}(0,95) \\
\operatorname{SC}(0,98) \\
\operatorname{RR}(1,10) \\
\operatorname{SP}(1,27) \\
\operatorname{RJ}(1,42) \\
\operatorname{DF}(1,85)\end{array}$ & $\begin{array}{l}\mathrm{SC}(0,94) \\
\operatorname{MG}(0,99) \\
\mathrm{MT}(1,00) \\
\operatorname{RS}(1,03) \\
\operatorname{SP}(1,33) \\
\operatorname{RJ}(1,39) \\
\operatorname{DF}(2,57)\end{array}$ & $\begin{array}{l}\operatorname{PE}(1,83) \\
\operatorname{GO}(1,86) \\
\operatorname{RO}(2,33) \\
\operatorname{RR}(2,70) \\
\operatorname{AM}(2,93) \\
\operatorname{AP}(4,55)\end{array}$ & $\operatorname{AM}(3,35)$ \\
\hline
\end{tabular}

Fonte: Elaboração dos autores a partir dos dados das Contas Regionais e dos Censos Demográficos, ambos do IBGE. Notas: na primeira coluna aparecem as classes de produtividade da mão-deobra setorial e nas células estão os estados com e sua situação relativa em relação à produtividade média do País, normalizada a 1. 